\section{A LIGHTER-THAN-AIR SYSTEM ENHANCED WITH KINETIC LIFT}

\author{
M. Leroy Spearman * \\ NASA Langley Research Center \\ Hampton, Virginia 23681
}

\section{$\underline{\text { Abstract }}$}

A hybrid airship system is proposed in which the buoyant lift is enhanced with kinetic lift. The airship would consist of twin hulls in which the buoyant gas is contained. The twin hulls would be connected in parallel by a wing having an airfoil contour. In forward flight, the wing would provide kinetic lift that would add to the buoyant lift. The added lift would permit a greater payload/altitude combination than that which could be supported by the buoyant lift alone. The buoyant lift is a function of the volume of gas and the flight altitude. The kinetic lift is a function of the airfoil section, wing area, and the speed and altitude of flight. Accordingly there are a number of factors that can be manipulated to arrive at a particular design. Particular designs could vary from small, lightweight systems to very large, heavy-load systems. It will be the purpose of this paper to examine the sensitivity of such a design to the several variables. In addition, possible uses made achievable by such a hybrid system will be suggested.

\section{Introduction}

With conventional airships, the load-carrying capability and the maximum operational altitude are functions of the volume of the lifting gas. To increase the load-carrying capability or the maximum operational altitude requires an increase in the gas volume which, in turn, results in an increase in the hull length and/or diameter. The use of twin hulls, as proposed herein, would permit an increase in the volume of gas without an increase in overall length. Connecting the twin hulls with a wing would, in forward flight, result in an added increment of kinetic lift that would be a function of the airfoil shape, the wing area, the flight speed and the altitude. This added increment of lift would be used to permit very heavy loads to be carried to an operational altitude greater than that obtainable with buoyant lift alone.

\footnotetext{
* Senior Technical Specialist

Systems Analysis Branch

Associate Fellow, AIAA
}

\section{$\underline{\text { Discussion }}$}

The Concept. - The proposed concept of a twin-hull airship with a connecting inboard wing is an outgrowth of a concept of an inboard-wing airplane that has twin fuselages. The inboard wing, twin-fuselage airplane was conceived as a means for doubling the capacity of a conventional airplane without extending the length and span dimensions over that of the conventional airplane. The application of the concept to an airship provides for a length reduction for a given volume or a volume increase for a given length.

Operational Factors. - The operational capability for this type of hybrid airship is a function of the buoyant lift provided by the lifting gas and the kinetic lift generated by aerodynamic forces on the inboard wing. The buoyant lift depends on the volume of the lifting gas and increases as the volume of gas increases. The kinetic lift generated by a wing in forward flight can be determined from the relation Lift $=C_{L} S q$ where $C_{L}$ is the lift coefficient for a given wing, $\mathrm{S}$ is the planform area of the wing, and $\mathrm{q}$ is the dynamic pressure of the airstream. The lift coefficient is a function of the airfoil shape, the angle of attack and, generally, the wing aspect ratio (ratio of span to chord). The variation of lift coefficient with angle of attack varies directly with aspect ratio and reflects the loss of lift at the wing tips. The inboard wing, bounded by large bodies at each end, effectively has an infinite aspect ratio and should have no loss of lift due to tip flow. S is the wing area and would be constant for a given design. The dynamic pressure of the airstream, $q$, is a function of the static air pressure and the flight velocity. The static air pressure, in turn, is a function of altitude and decreases with increasing altitude. The dynamic pressure for a given altitude increases with increasing flight speed and, for a given speed, decreases with increasing altitude.

Kinetic Lift Potential. - From these relations the kinetic lifting potential of a wing can be determined for various altitudes, Mach numbers, wing area's and angles of attack. For example, the kinetic lift potential for a wing with an NACA 23012 airfoil shape and an arbitrary area of 10,500-square feet has been estimated. The estimates indicated that for $\mathrm{M}=0.1$ at an altitude of 10,000-feet and a 4-degree angle of attack, the kinetic lift would be about 150,000 pounds. 
This would be increased to about $1,500,000$ pounds at $\mathrm{M}=0.3$ and to about $4,250,000$ pounds at $M=0.5$. It should be noted that the wing lift could be increased through trailing-edge flap deflection rather than by increasing the angle of attack. These estimated values of kinetic lift are illustrative only and would vary for other airfoil shapes and other wing areas. It is evident, however, that substantial amounts of kinetic lift are achievable in forward flight that would enhance the performance of this type of hybrid system.

Speed Considerations. - Generally, airships have been somewhat limited in speed. This limitation has been imposed by a combination of factors including aerodynamic drag, structures and propulsion. Improvements in these areas are now readily available. Through the use of new composite materials it should be possible to produce strong yet lightweight structures. In addition, it should be possible to shape these structures into low drag configurations through blending and contouring. Reduction in drag could be coupled with new high-thrust engines so that speeds considerably greater than that of past airships could be achieved.

Control. - Some aerodynamic controls could be utilized. An example would be the use of flaps on the wing to adjust the lift. Vertical surfaces might be used to aid in directional control. In particular, cycloidal propellers and deflected jets could be used to provide control in all phases of flight as well as in ground handling. A control room could be housed in a gondola arrangement beneath a hull or in the leading-edge vicinity of the wing

Size Considerations. - The twin hulls would provide the volume for the lifting gas although some space might be reserved for other cargo. The wing could also provide a substantial amount of volume. For example: with an arbitrary hull length of 400 feet and a wing chord of 200 feet, the maximum thickness of a $12 \%$ wing would be 24 feet. While substantial volume is available on the inside of the structure, it is possible to attach cargo pods to the underside of a portion of the wing.. Such an arrangement of pods could be designed for rapid loading and unloading of cargo. The size and the attendant cargo capacity coupled with the operational features make the hybrid airship concept a good system for long-range heavy cargo missions.
Concept with Regard to Conventional Systems

Logistic Support. - Logistic support missions may require the rapid transport of substantial amounts of material including large and heavy items. Surface ships can accommodate such loads but are limited in speed and in suitable port facilities. Conventional air transports can fulfill the speed potential but are limited in cargo size and weight capacity. In addition, conventional aircraft are sometimes limited in basing facilities.

The hybrid airship appears to be a potential system for accomplishing stringent logistic support missions.. Such a system can provide for transporting very large and heavy items at a reasonably high speed. In addition, the airship system would be capable of loading or unloading at almost any location.

Commercial Air Transport. - The use of an airship concept as part of a commercial air transport system suggests some implications with regard to some concerns that result from the operation of transport aircraft. These concerns include the community noise problems during takeoff and landing; air and ground traffic congestion problems and the related delays to the passenger; weather related delays; fuel efficiency; and safety.

Airport Congestion and Delays. Congestion and delays often occur on the ground when many airplanes are required to use the same taxiways and runways. These problems could be alleviated with an airship using the buoyant mode for vertical takeoff and landing since taxiways and runways would not be required.

Delays in air traffic movement occur when adverse weather, particularly ice and snow, results in runways becoming unusable. Such conditions may cause an airport to be closed for a matter of several days and will have a detrimental effect on passenger and cargo movement. With the buoyant capability of an airship, however, flight operations would continue regardless of ice and snow on the ground.

Community Noise. Noise levels at and near an airport are not only annoying but may also be a hazard. The primary source of noise is that caused by the jet engine. This noise begins with the engine run-up at the gate, continues through 
the ground taxiing, and becomes increasingly objectionable as maximum power is applied for takeoff and climb-out. An additional source of noise occurs during the landing phase when maximum power is applied to produce the reverse thrust for braking. These noises, which are engine-generated, could be eliminated or substantially reduced with an airship since very little engine thrust is required at ground level

Airport Compatibility. - As the size and weight of conventional aircraft increase, the problems of compatibility of the aircraft with the airport become more critical. These problems include the clearance required for aircraft to pass on the taxiways; the access of the aircraft to the passenger loading gates; and the ground load limitations imposed by the strength of the runways, taxiways, and parking aprons. The excessive size of an airplane may preclude operation from some airports whereas an airship can operate from many areas that are not accessible to an airplane.

Fuel Efficiency. - In addition to the fuel required to fulfill the mission requirements, an airplane must carry reserve fuel to allow for holding times necessitated by ground and air traffic delays. For an airship most of the fuel would be used in meeting the mission requirements with very little fuel necessary for ground or air traffic delays.

Safety. - For an airplane, the loss of power or a malfunction of the control system can have serious consequences. Such events pose no serious problems for an airship because it can hold its buoyant position. The airship also avoids the trailing wake vortex hazard that may be encountered by conventional airplanes.

Other. - An airship operating at a lower flight speed than a conventional airplane might have an overall point-to-point time advantage through avoiding traffic delays and weather effects. In fact, it is possible that an airship might complete some flights that could not be made at all by an airplane.

\section{$\underline{\text { Epilouge }}$}

The concept of a lighter-than-air system in which the buoyant lift is enhanced with kinetic lift that is provided by an inboard wing suggests several possibilities:

- A means for increasing the lifting capacity of an airship while maintaining or reducing the overall length.

- The kinetic lift developed in flight permits a greater payload/altitude combination than that which could be supported by buoyant lift alone.

- A means of providing for logistic support missions with large, heavy loads and with no basing constraints.

- A means for alleviating some of the concerns of commercial air travel such as airport congestion; flight delays; community noise; airport compatibility; fuel efficiency; and safety. 